Meta

Journal des traducteurs

Translators' Journal

\title{
Pragmatic Evolution of Translation in an Industrial-Scale Translation Service
}

\section{Peter Gawn}

Volume 31, numéro 2, juin 1986

URI : https://id.erudit.org/iderudit/002832ar

DOI : https://doi.org/10.7202/002832ar

Aller au sommaire du numéro

Éditeur(s)

Les Presses de l'Université de Montréal

ISSN

0026-0452 (imprimé)

1492-1421 (numérique)

Découvrir la revue

Citer cette note

Gawn, P. (1986). Pragmatic Evolution of Translation in an Industrial-Scale Translation Service. Meta, 31(2), 220-223. https://doi.org/10.7202/002832ar d'utilisation que vous pouvez consulter en ligne.

https://apropos.erudit.org/fr/usagers/politique-dutilisation/ 
PRAGMATIC EVOLUTION OF TRANSLATION IN AN INDUSTRIAL-SCALE TRANSLATION SERVICE*

\section{INTRODUCTION}

I should like to begin this paper with two introductory remarks : 1) although I have taught translation, I have never studied it ; 2) although I have worked as a translator, most of my relevant experience has been as a manager of translators and translation services. My approach is therefore, as befits the title of this paper, a pragmatic one : it is a non-theoretical approach. Indeed my knowledge of translation theory and of linguistics in general is rudimentary. But as director of one of the largest translation operations in the world, my knowledge of the reality of translation in the workplace is considerable, and I am pleased to have the opportunity to talk about it.

In preparing this paper, I decided to introduce it by way of three quotations. The first is from an essay by Boris Pasternak entitled "Notes of a translator". He says : "The translation must be the work of an author who has felt the influence of the original long before he begins his work" 1 . I take this remark as an example of the ideal approach to translation in which the translator immerses himself in the author's work, takes the time required to carefully render it in the target language and then, ideally, puts it away for review at a later date before releasing it. I am sure we would all agree that this is how translation should be done. My second quotation is from Professor Wolfam Wilss's paper "The Prospects for translation courses from the point of view of the University of the Saarland", March 19842. In it, Prof. Wilss notes : "There are signs that the type of university training given to prospective translators no longer corresponds to the concepts and requirements of the profession in both the national and international spheres of translation activity". If I did not feel that Prof. Wilss was right, I would not be here now. My third quotation is anonymous, but typical, if extreme. It comes from the mythical client of our translation service who presents his text and says "Type this up in French". A lot of distance separates the ideal creative work implicit in the quotation from Pasternak, and the requirements of the client as evident in the "Type-it-up in French" approach. These three quotations provide the backdrop for this paper, since I want to identify the factors, or some of them at least, that are obliging translators to depart from the traditional holistic approach to the act of translation and to adopt a more fragmented and less artisanal methodology.

But first, a few words about the context.

\section{CONTEXT}

Canada has two official languages, French and English. The Canadian government must therefore provide all its services in both languages. To do so, it relies heavily on the government's Translation Bureau, in which I work. Although the Translation Bureau has a fairly large simultaneous translation or interpretation division, this paper is only concerned with issues affecting the translation of written texts. The volume is enormous, about 850 thousand pages a year. For various reasons, most of the texts translated are written in English, so that about $90 \%$ of the work is from English into French. This service is provided without cost to about 150 government ministries and agencies, whom we refer to as the clients. The demand for translation is characterized by a very uneven workflow and by a very wide range of subject areas. The work is done by some one thousand staff translators, all permanent fulltime civil servants, backed up by a pool of freelance translators working under contract for each text they accept. It will readily be appreciated that this concentration of translation effort causes the government translation service to exercise a dominant influence on all aspects of the profession in Canada. 
What are some of the factors I referred to earlier that affect the way translation is done?

\section{FACTORS}

First is undoubtedly the time the client provides for translation, the annoying problem of deadlines. Some of these are inevitably too short. I say inevitably because they are related to political considerations. I mean for example that when a minister is to make a speech or issue a press release on a politically sensitive matter, the final text will not be ready in the original language until the very last moment - a matter of hours, often night hours - before the delivery time. The same often applies to documents to be submitted to the cabinet or to other top level decision-making committees. Often, too, the very structure of bureaucracy, with its various hierarchical strata, each of which has to approve a document on its way to the top of the pyramid, creates a situation whereby the document must be dispatched immediately the minister, for example, has approved it. Here again translation cannot be allowed to retard the process. And also, the author of a document, who may have spent days, weeks or even months preparing it, is naturally anxious to see it published once he is through with it, so that the translation service is again put under considerable pressure to produce quickly.

To this first factor of deadlines must be added a second, namely that the resources, particularly human resources, the government is prepared to allot to translation are limited. Staff translators have to be allocated carefully to the various work units in such a way that they can cope with the urgent, shorter, day-to-day texts, the longer documents being sent to central units or to freelance. As a result, translators assigned to units in the various ministries are constantly working under pressure.

A third factor is the specialized nature of many texts received for translation and the wide variety of subject matter. Since technical and scientific documents are best translated by people who have the subject-area knowledge they are generally handled in central specialist units or, again, by freelances. It is thus not usually possible to assign this type of document to translators in the ministerial units, much as they would sometimes like to tackle them.

What effect do these three factors in particular have on the way translation is done?

First, because of the short deadlines it is usually impossible to do more than the essential research : compromises are often called for, since it is sometimes not possible to contact the person who wrote the document. Second there is rarely ever time to put the translation on one side and review and improve it a day or two later : the first draft is often the final version. Third because again of time restraints, but also because of limited resources, revision by another translator or reviewer is minimal. There is an increasing tendency to cut out the revision phase, and to promote the concept of translator autonomy, althought it is by no means clear if this tendency is motivated on professional grounds or for reasons of economy. Fourth, it is frequently necessary to divide a text, such as a speech, among a number of translators, in order to meet the time frame. The effect of this on quality, style, and professional integrity is obvious. Fifth, the translator is forced to rely on the help of his colleagues in the auxiliary services - terminology and documentation - to do the direct and indirect research that has traditionally been considered an important part of the professional act and as essential to the development of the translator's knowledge and competence. Sixth, few translators can decide what text or type of text they would like to translate. They must do the best they can with whatever work is assigned to them, bearing in mind however that specialist translators normally work only in their area of specialization. And seventh, translation is viewed by some as a production-line operation in which the translator assembles a product, or part of a product, using the terminology and precedents provided to him by other parts of the production unit. The translator is then no longer the artisan of his work, but rather a member of a work team, with more or less autonomy for the execution of his task.

\section{QUALITY}

In this context, the question of quality is a difficult one. As I mentioned earlier, the translation service deals predominantly with texts prepared in English and which are to be published in both English and French, or in French only. The finished translation must not appear to be a translation. Both languages are of equal value, therefore the government must not give the impression that it works in English and relies on translation for the production of the French version. Whether or not it is in fact possible to produce two authentic texts via the translation process is a fascinating question which I shall not attempt to deal with here. It nevertheless remains true that our service does in fact write a very large proportion of the French texts that come from the Canadian government, and this undoubtedly has an influence on the quality of French in Canada. The immediate client, the commissioner or principal, is often in no position to assess the quality, and in fact is frequently not interested in doing so, since his concern is only to make sure that a French text is produced. The ultimate client, the reader to whom the French version is addressed, rarely expresses an opinion on the quality. It is therefore up to the translation service to monitor quality. This is done either as part of the production process, by a revisor or reviewer, or through regular, random sampling by the quality control unit.

We apply a quality evaluation instrument which is used to grade translations on a five-point scale, after comparison of text segments. Designed to be objective, the instrument nevertheless involves subjective judgements, with a fair degree of convergence. Since we were not certain about the validity of 
the instrument, we had it evaluated last year by a consultant, whose principal conclusion was that there was no point worrying about the effectiveness of the instrument, the method, until the management team agreed on what constituted a good translation. His study showed that there was no real consensus on this critical issue. To give just one example : what is a good translation of a poor SL text? A poor TL text ? Opinions differ. We also do a scientific sampling of client satisfaction including quality evaluation. The results appear to indicate a direct correlation between quality assessment and satisfaction with the service provided. In other words, if the translation is provided on time and in the format requested, the client rates the quality as good.

One consequence of the importance attached to internal quality control is that the translator often feels he is working for the revisor, who is usually his boss in any event, rather than for the client or the reader. The result often is a French text that is too literary, too stylish, for the consumer, but also, alas, a text that still bears the marks of a translation. Our critics complain that we produce a translationese that is the hallmark of the government's publications in French.

\section{MACHINE AIDS}

While quality remains a concern, like all government services a period of financial restraint we need to produce more with the same or fewer resources. Obviously therefore the translation service has to see what the electronics industry can do for it. We have been using word processing systems in our typing pools since they first became available. But we also have a number of translators who work directly with word processors, and in some cases their translations are revised on the screen by the reviser. In this way it is possible to avoid costly retyping and even the production of hard copy since some clients prefer to receive the translation on line, through a communication device, or on the diskette. Many translators dictate, and their texts are then entered into word processors by specially trained operators. Others type, using electric or electronic typewriters. Few if any write their texts by hand. The translator is thus increasingly mechanized, and needs to be able to work easily with the different equipment available to him. A second electronic tool is of course our terminology bank. Accessible through terminals located in every translation unit, the bank provides instant on-line access to 750 thousand terminology fiches or records. As for automated translation, we operate the MÉTÉO system which handles the weather synopses across Canada with an $80 \%$ success rate. Human translators intervene, through a terminal, when the computer experiences difficulty. We have evaluated and tried various commercial computer-aided translation systems but have not so far adopted any of them. There is no doubt however that if we are to translate aircraft maintenance manuals and other technical documentation for the Defence
Department, only the computer can do it, since there are not enough translators to cope with the hundreds of thousands of pages involved. Our technology division is responsible for pursuing this activity.

What becomes of the human translator in view of these existing and forseeable developments? He will have a range of tools at his disposal, and will have to choose the most suitable one for handling any given assignment. He may become an adjunct to the computer, monitoring its performance and proposing modifications to programmes or equipment. He may need new skills to process the output from machine translation systems. In some situations he may not be needed at all, except as a consultant to a client operating his own automated system. And once it becomes possible to generate SL text on a computer, then translation into a TL would be an integral part of the system. We are experiencing a revolution in communication, that will have an enormous impact on the role played by the translator in the years to come. And this brings me to the need for research and study of various aspects of the profession, which is in full evolution.

\section{ACADEMIC EXAMINATION}

As a manager of a large and busy translation service $I$ believe that there are many subjects that could profit from academic scrutiny. These are subjects of direct interest, but which the practitioner does not have the time or the resources to develop fully. Some of them have already been touched on : others are new. Here is a list

1. Evaluation of quality. This topic has been dealt with briefly above and does not need further discussion here.

2. Evaluation of the potential of a candidate translator. Some work has been done in this area, but no measurement tools are available as far as I know.

3. Measurement of the competency of a working translator. What standards would be used, and how objectively can they be applied?

4. Post-hiring training. What is the best way for the employer or the translator to maintain proficiency and develop ability after a translator has been hired?

5. Production standards. How much work in pages or words should a translator produce in a year?

6. Work-unit size and composition : what is the optimum size and make up of translation units. Is there a point beyond which any increase in size reduces the efficiency of the unit?

7. The need for computer literacy : what training should student translators and practicing translators be given to help them make the best use of computers and other electronic aids to translation?

8. What effect will the computer have on language and what role should the translator exercise?

9. What mechanisms exist or could be developed to provide a clearing house for information on the state of the art in translation? 
10. What is the future of translation and how can we prepare to deal with it? and finally

11. what interaction should there be between employers of translators, schools of translation, professional associations and trade unions, where they exist?

Study of these and other questions should certainly help to advance the profession of translation.

\section{THE PROFESSION}

In Canada, at least, the profession of translation is not clearly or officially recognized. Perhaps 1 should have added another topic to my list, namely, what constitutes a profession, how should translation be organized so as to constitute a profession, or should it be a profession? Perhaps this is a question that cannot be answered until there is a clearer consensus among the interested parties as to what constitutes a good translation, since the profession can not exercise a control over the service it provides if is not certain just what that service should be. Some clients are uneasy with anything that strays too far from a literal translation. Others say they want an adaptation - not just a translation. Hence the need for a typology of translation and a corresponding range of products that can be offered to respond to the client's need. There is a continuum from the one extreme of word-for-word translation to the other extreme of free adaptation. Based on his skills, the translator could take up a position within that range, or possibly operate at any point on the continuum. But one thing I think is clear : translators need to fix the parameters for their work, establish the basic conditions under which they will accept a particular job, and act together to ensure that their colleagues respect these conditions.

I have attempted in this paper to bring out some of the factors that a large service like ours, and probably in the United Nations and the EEC, affect the way translation is done and distort the methodology traditionally associated with the translation act. Some of what I have said is peculiar to Canada and particularly to a situation in which translation is being done for publication rather than for the information of the client or user. However, the methods that we will be developing will certainly influence user expectations in North America, and could well have an effect on practitioners and clients on the other side of the Atlantic.

PETer GaWN, TRanslator, otTaWa

Notes

*Paper read at the 1984 Congress of the International Association for Applied Linguistics, Brussels.

1. B. Pasternak (1984) : Selected Papers, Penguin, p. 12.

2. Proceedings of Malaysia Conference, March 1984. 